\title{
Cadmium Chloride
}

National Cancer Institute

\section{Source}

National Cancer Institute. Cadmium Chloride. NCI Thesaurus. Code C45894.

A whitish, crystalline, inorganic compound that forms toxic fumes of cadmium oxides when heated. Cadmium chloride is used in electroplating, printing, photocopying, dyeing, mirrors, vacuum tubes, lubricants, analytical chemistry and as a chemical intermediate to produce cadmium containing pigments and stabilizers. Exposure to this substance irritates the eyes, skin and respiratory tract and causes damage to the lungs resulting in shortness of breath, chest pain and pulmonary edema, and can also damage the kidneys causing proteinuria and decreased renal function. Cadmium chloride is a known carcinogen and is associated with an elevated risk of developing lung cancer. ( $\mathrm{NCl05)}$ 